\title{
Catalogs, Codes and Bibliographical Control
}

Miss Radford is library assistant, Public Library, New South Wales, Australia.

W HILE the Librarian of Congress cannot be named as the sole prompter of this paper, his statement to the executive secretary of the American Library Association that he hoped to receive in connection with the problem of bibliographical control, "suggestions, however wild or ideal," makes him at least partly responsible. To all who are interested in this problem his invitation is so broad as to constitute a challenge. It was made in his letter which transmitted Paul Vanderbilt's essay "National Bibliography and Bibliographical Control," prepared for comment and criticism at the June 1947 meeting of the Association.

From that essay I take my point of departure: "While a number of international codes have been proposed for adoption, it seems to us that insufficient thought has been given to card production as the first step in international bibliographical control." My remarks will be concerned with a technique which may encourage within nations the preparation of cards acceptable to others and as a corollary the use of cards prepared by others, and with the division of bibliographies by period. They will be related, then, to the "units of nations and years" which Vanderbilt assumes must be used in

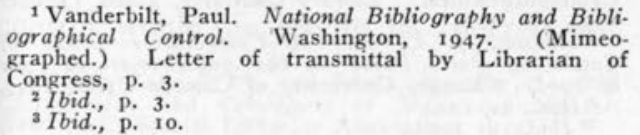

any basic listing. Where they appear to have implications for the making of library catalogs, these implications will be examined, because although we cannot hope to kill bibliography and cataloging with one stone, we must aim at this to complete either task.

Books are of course only one type of material to be recorded, but for the purposes of this discussion they will be the type. They can be recorded in many categories, but are mainly listed as items or as contributions to subject knowledge. Records of the latter kind cannot avoid incompleteness or duplication, because of varying judgments on particular titles, polytopical books and overlapping subjects. Vanderbilt points out that with subject bibliography there is in fact "a great desire to reduce the mass selectively." 4 Those who have studied the bibliography of science often express the need to get back of publication, as it were, and evolve schemes such as Bernal's "project for scientific publication and bibliography." ${ }_{5}$ This paper will be limited to the listing of books as items.

Complete control is unlikely to be reached. Our aim should be to approach it. It must be world-wide, but there is little likelihood of its being centralized. The breakdown suggested by Vanderbilt is the national one. (This is on the way to his notion of "cataloging at the source," 6

\footnotetext{
Loc. cit. Bernal, J. D. The Social Function of Science. New York, Macmillan, 1939, p. 449-57.

$\checkmark$ Vanderbilt, op. cit., p. 9.
} 
which has been practiced to a limited extent in Australia since the beginning of 1946 . There the Commonwealth National Library at Canberra receives advance copies of all works to be published by Angus \& Robertson Ltd., who have their own printing establishment and retail store and are the main publishers in the country. The National Library supplies the firm with copy for catalog entries which are available on standard cards simultaneously with publication. Libraries thus receive books and cards from the same source, and anyone can obtain either without the other.) An alternative to national lists would be those compiled by language, of which the Cumulative Book Index is a good example.

Within each nation the record might be edited by the library which acquired the greatest proportion of the books, assisted in the preparation of copy by cooperating institutions. Copyright laws, library deposit privileges enjoyed under them, the existence of a national library and its conception of its functions, would be the kind of factors influencing choice of editor. In England, for example, a decision would need to be made between the British $\mathrm{Mu}$ seum and National Central Library, whereas in the U.S. the question of a choice would be unlikely to arise.

Let us assume, then, the preparation and distribution by each nation of a record of the books published within its boundaries. Let us assume, further, that the record will be in the form of printed cards of standard size, which will serve the needs of both national bibliography and library catalogs. As indicated above, the bibliography may be compiled largely from catalog entries, in which case its preliminary card form will be dictated. For easier distribution, consultation and storage it is likely to appear also in book form, but the exchange of cards between nations would permit any desired intercalations into bibliographical files as well as the distribution of entries to libraries.

\section{Units of Nations}

In what terms shall the books be described? They should be described in accordance with the cataloging rules of each country, because the descriptions will be made largely by libraries and are to serve their purposes as well. Countries in which no code is used are unlikely to be sufficiently advanced bibliographically for effective cooperation; many will need to decide upon one code amongst a number. The descriptions will vary, as do the rules, unless an internationally acceptable and accepted code is evolved. Such a code is unlikely. In I934 Hanson foresaw a wait of 50 or 100 years for agreement on the entry of works by two or more authors. ${ }^{7}$ The title of his study of codes is long but relevant: Comparative Study of Cataloging Rules Based on the Anglo-American Code of 1908 , with Comments on the Rules and on the Prospects for a Further Extension of International Agreement and Co-operation. ${ }^{8}$ The book deals with rules "which have a direct bearing on headings or entry words," which agreement is considered essential for "consequent co-operation." 10 It could be argued that if there were a real desire for cooperation there might be some hope of consequential agreement.

It may be, however, that unanimity on headings and entry words is unnecessary. Entries could be prepared without headings, but with tracing notes which list first the recording heading in accordance with the rules being followed. (By "recording

\footnotetext{
7 Hanson, J. C., M. [Review article] "The Belgian Cataloging Rules." Library Quarterly, 4:660, October

${ }_{8}^{1934}$ Hanson, J. C. M. A Comparative Study of Cataloging Rules Based on the Anglo-American Code of 1908. Chicago, University of Chicago Press, 1939. 9 Ibid., p. 134.

10 Ibid., p. 135 .
} 
heading" I mean that under which the book would be entered in a single-entry bibliography.) By analogy the users of the cards would decide on the heading needed for each entry in conformance with their own codes. The German bureau handling an American card which listed a department of government as recording heading would file the entry by personal author or some part of the title; the American bureau dealing with an English card for a book by a nobleman would vary the form of recording heading but not the choice. Those working on the adaptation of entries would need to know the important differences in codes; a knowledge of them is necessary already for effective use of foreign catalogs and bibliographies.

The idea of preparing entries without headings is not new. It has been described as a cataloging technique in Boggs and Lewis' The Classification and Cataloging of Maps and Atlases, ${ }^{11}$ and is mentioned by John Metcalfe in notes written by him for the library school in Sydney as a possible solution of the problem of indicating the filing of secondary author entries in a dictionary catalog using unit cards. Sets of cards prepared in this way have been distributed by the Library Board of New South Wales to public libraries availing themselves of the board's central purchasing of books and central cataloging. Where entries are being made for homogeneous collections in libraries of a single type there is least justification for the form under consideration. In New South Wales it has meant that the same entries are used, with different forms of author heading when desirable, in the small rural libraries and in the state reference library. The value of the plan as a contribution to bibliographical control would lie less in its concrete ad11 Boggs, Samuel W., and Lewis, Dorothy C. The
Classification and Cataloging of Maps and Atlases. New York, Special Libraries Association, 1945. vantages, though these would not be negligible, than in its effect on the thinking of catalogers about differences they believe to be insuperable barriers to cooperation. It does not remove these barriers, but may be said to walk around them. No departure from, or modification of, the principle of author entry is implied, but only the provision of room for choice within the framework of accepted codes.

In each country the cards would be used in library catalogs. For these they would present few difficulties and some advantages. Conservatives among catalogers may argue that a heading is an integral part of an entry. It is indeed so if "the principal paragraph of the entry"12 does not include the author's name, and the Library of Congress Rules imply it is so when they say that "the title (together with the author's name as heading)" ${ }_{13}$ is usually sufficient data in the entry to distinguish between works. However, they declare later on that "the statement of authorship . . . is to be incorporated in the catalog entry only if it is necessary for one of the following purposes," ${ }^{14}$ implying that if the name of the author appears only as heading it is not "included in the entry," 15 and that the heading is separate from the entry. The accepted definitions offer no clarification, but it is the terminology that is obscure, not the intention of the compilers of the Library of Congress code. There is need for formalizing what is meant by phrases such as "the principal paragraph" and "the body" of an entry, as well as the relationship between entry and heading.

These are merely verbal difficulties. Catalogers would receive (and prepare) cards which listed in the tracing note the main entry heading in accordance with

\footnotetext{
12 U.S. Library of Congress. Rules for Descriptive Cataloging. Washington, 1947 , p. 6 (2:3).

13 Ibid., p. 7 ( $2: 8)$.

14 Ibid., p. 15 (3:i5)

15 Ibid., p. 15 (3:16).
} 
their own or some other code. Cards received from countries using a different code could be edited at the central bureau before distribution to avoid overlapping effort in deciding on main entry if this were considered desirable. The tracing note would be a record of all entries made for a book, instead of for all but one, as at present. Whereas the main is now the only entry which theoretically needs no additions, under the new scheme this would be true of a title entry following the order of the words on the title page.

A more logical grouping of the items in the tracing note would be possible. Neither of the groups at present used on Library of Congress cards is consistent, subject and form entries being together in one, and title and contributor entries in the other. Also differences are suggested when they do not exist; in works of joint authorship, for example, the relation of each author to the book is frequently the same but looks different from the cards describing the book. Details of this kind are unlikely to interest or mislead users of catalogs, but when they result in illogical indexing because catalogers themselves are confused any improvement in tracing notes is worthwhile. One indication of this confusion is the varying notions of added, secondary and general secondary entries, and one result of it is the use of identical headings for works about a subject and for works which are examples of a form. There are entries for contributors to books, that is, for persons and corporate bodies who have been actively connected with them; entries for subjects of books; for forms exemplified; for titles; and, to approach completeness, entries for works which include the one being catalogued-the most usual being series entries.

The A.L.A. Cataloging Rules have been prepared with dictionary catalogs "particularly in mind." ${ }_{16}$ They devote a great deal of thought and space to the recommendation of main entry heading for various kinds of book. Whenever a choice is entailed an added entry is to be made under the heading not chosen for main entry. I do not wish to minimize the importance of author main entry or the need to determine one heading which should be chosen before all others for arranging descriptions of books in bibliographies and single-entry catalogs. These both seem to be essential to any scheme for national and international bibliographical control. However, energy and time should be saved in many quarters if it were more widely realized that in dictionary catalogs using printed unit cards the main entry differs from added entries in function only. Even the tracing notes, the basis of the structural function, appear on all entries. Main entries are adapted by the alteration of tracing notes to suit each library, and are generally used in large catalogs for the listing of copies or editions of a work not repeated under other headings for the same work. The former would not be necessary in the library preparing the entries; the latter is a form of selective cataloging rather than a special property of main entries. Their structural function is particularly clear in classified catalogs, which have in effect two main entries, that in the classed file recording all but one of the added entries listed on $\mathrm{Li}$ brary of Congress cards by arabic numera!s, and that in the author-title file recording all listed by roman numerals. The point I want to make is that the importance of the concept of main entry has been over-emphasized in our thinking about dictionary catalogs.

The main entry heading would be, by agreement, the one listed first in the tracing notes for contributors. (Boggs and Lewis list it first in the subject and form

16 A.L.A. Cataloging Rules for Author and Title Entries. $2 d$ ed. Chicago, American Library Associa. tion, 1949, p. xx. 
group, since they choose for the heading the name of the area with which a map deals.) ${ }^{17}$ Added entries for contributors would be made by adding their names to the cards, and the problem of indicating the filing by heading and then by title would disappear. Subject and form entries would be made by adding subject or form, and author, unless subarrangement by date is preferred, or even by title, for which a case could be made. By combining a suggestion made by Ralph Ellsworth ${ }^{18}$ and a practice described by Mortimer Taube ${ }^{19}$ we could compile catalogs by adding to cards only the call number. Each author and subject could be indicated by a guide card perhaps bought from the central bureau, or if this proved too bulky, by a projecting movable tab which would be attached to the first entry under each heading and which would indicate that all entries between this tab and the next were under the same heading. If we could to this extent make our catalogs visible index files we would remove a common cause of confusion among readers -the filing of entries with a variety of headings behind a single guide card. The place where a particular card should be filed would be indicated by marking in some way the appropriate heading in the tracing note.

The possibility of omitting headings in library card catalogs is of interest if there is likely to be a move back to catalogs in book form for the whole or parts of collections, made by some kind of photographic reproduction of the cards already in use. The Library of Congress Catalog of Books Represented by Library of Congress Printed Cards Issued to July $3 \mathrm{I}, 1942^{20}$ is of

17 Boggs and Lewis, op. cit., p. 39.

18 Ellsworth, Ralph E., and Kilpatrick, Norman L. "Midwest Reaches for the Stars." College and Research Libraries, 9:136-144, April, 1948.

19 Taube, Mortimer [Remarks at Columbia University, Dec. 5, r 947 ].

so U.S. Library of Congress. Catalog of Books Represented by Library of Congress Printed Cards course the prototype. While no one would describe this as a mongrel publication it possesses features unusual in a book catalog, as its compilers well know. Its appearance completed the circle of book form to card file and back to the book, but book catalogs are always likely in the future to be based on cards. Before cards were printed, the amount of information given in various entries for the one work varied, but when printing was adopted, and with it unit cards as its cause and result, catalogers appreciated an advantage of cards in addition to that of easy intercalation. This was that an entry took up the same amount of space in a drawer whether it was brief or ample; adequate information could be given about a work wherever it appeared in the catalog. This economy in card catalogs becomes a waste of space in books. Few catalogs in book form would be made with more than one full entry for each work described. I have come across only one bibliography which has the luxury of unit entries under author, subjects and title for each work recorded. ${ }^{21}$ Catalogs which appear in book form, then, are likely to be of entries arranged by one principle, for example subject, with an index arranged by another, for example author. This method meets the needs of people approaching works from both angles, and the inconvenience of referring from a point in the index to an entry or entries would be part of the cost of the advantages of book catalogs.

Book catalogs with more than one entry for each work listed are unlikely, then, to be compiled by photographing all the cards which perform the same functions in the card catalog. A tyranny of a different sort was encountered in the making of the Cata-

Issued to July 3I, 1942. Ann Arbor, Edwards Bros., $1942-46$.

${ }_{21}$ Gourley, James E., and Lester, Robert M. The Diffusion of Knowledge: a List of Books Made Possible Wholly or in Part by Grants from Carnegie Corpo. ration of New York... I9II-1935. Philadelphia, Press of W. F. Fell Co., 1935. 
log of Books, a single-entry list. The description of each book took as a minimum the space required for each reduced card, even when most of the card was blank. It has been interesting to observe that from January 1947, when the Cumulative Cata$\log ^{22}$ first appeared, this waste of space has been overcome by the telescoping of each card to cut out blanks between the entry and the information at the bottom. In addition, "added-entry cross-references," ${ }^{23}$ specially set up, are included. Overlapping has not been used to avoid the repetition of the heading when there is more than one card under it. This would take less room and make for easier consultation, and discussion of it brings us round once more to the idea of preparing entries, for national and international purposes and for library catalogs, without headings, since their inclusion is a stumbling block to cooperation and their omission is easily made good at the appropriate stage and may even lead to their more intelligent use.

\section{Units of Years}

So much, then, for an effort to facilitate bibliographical control by Vanderbilt's units of nations. What of his units of years? We might intercalate cards indefinitely, but the cumulation of books would come to an early halt and a fresh beginning. Each country might keep more than one card file ; world output year by year, each nation in a separate file for an indefinite period, its own output also by year or perhaps decade. Microfilm or microprint could be pressed into service, and contiguous countries could collaborate in the setting up of regional bibliographical centers where distances and resources are both limited. With all care and planning, however, there would soon become apparent the need to break down the

\footnotetext{
${ }^{22}$ U.S. Library of Congress. Cumulative Catalog of Library of Congress Printed Cards, January, 1947: Washington, 1947-

23 Ibid., p. [r].
}

unity so laboriously built up. Because we are trying to keep pace with a stream of literature, periods seem to be almost a natural classification for our purpose. Thus the stream can be dammed at specific points in time. It is a choice between one tremendous file and a number of smaller but still large ones.

If we agree, then, that card files such as the Library of Congress union catalog cannot continue in one sequence forever, we must make a decision on when and how to divide them. One way would be to extract entries for works published before a certain comparatively remote year, perhaps I 800 , although studies by Pafford, ${ }^{24}$ Gosnell ${ }^{25}$ and Stieg $^{26}$ suggest that 1900 might not be too recent, and file all incoming entries for current books with the cards that are left. This sorting is not likely to be done by machine. It would be a costly business, and, what is more important, a recurring one. The alternative is to make a break in the present-a new file, say, for books published on and after Jan. I, I95I, to be continued for 50 or 100 or any number of years which proves workable. Present files would therefore be a record of the books published during the first 500 years of printing, a span which has no intrinsic virtue but is at least neat for reference. While we realize that bibliographies and catalogs made centuries ago are now almost solely of historical interest, as are the works they record, had their compilation been a continuous process there is not likely to have ever been a time when their compilers could have said: "This is a logical time at which to divide our lists." There is never a natural break in the stream. Bibliog(Continued on page 428)

24 Pafford, J. H. P. Library Co-operation in Europe. London, Library Association, 1935, p. 110.

${ }^{25}$ Gosnell, Charles F." "Obsolescence of Books in College Libraries." College and Research Libraries,

5:115-25, March 1944 "“ A Technique for Evaluating the College Library Book Collection." Library Quarterly, 13:44, January r 943 . 
libraries in other junior colleges which are considered comparable because of like situations and conditions; the compensation paid for work performed in comparable professions where duties and responsibilities are of equal weight.

In developing the pay plan, in addition to the above considerations the "Minimum library salary standards for 1948 " adopted by the A.L.A. Council Jan. 31, 1948, should be kept in mind and should form the basis for a pay plan for junior college libraries.

If you will permit me to attempt a brief summary of the place of classification and pay plans in junior college libraries it will be the following: Because of the size of the staffs of junior college libraries, problems of effective personnel administration in the libraries will be on a small scale and usually on a personal basis, but will be of as great importance to the junior college as are large scale problems in the largest libraries to their parent institutions. Consequently a junior college library classification and pay plan which may require only one or two pages for presentation is as significant and of as much importance in its place as is the 576-page classification and pay plan of the Library of Congress.

\section{Catalogs, Codes and Bibliographical Control}

\section{(Continued from page 40o)}

raphers must make them arbitrarily, and in a few decades they might well prove something of a blessing. It is not so much because the present is too much with us as because it is always with us that there is urgent need for some sort of decision along the lines I have indicated.

While a similar problem confronts those responsible for the catalogs of large libraries, it is more complicated. Books are likely to be stored at a distance because of infrequency of use. This will be closely related to age, but much current material will also be so stored. Rare books, on the other hand, are likely to be kept near the heart of the library, for safety and display if not for use. A library like Harvard's could print an author catalog of its present holdings from cards withdrawn from the catalog. The cards need not be reinserted. The accumulation of arrears and the continuing purchase of old works would mean that the card catalog would not be limited to entries for works published after a certain date, and that the printed catalog would not contain entries for all works before a certain date. The size of card catalogs may be attacked quite differently, and has already received much thought and some action.

In conclusion I should like to repeat that if bibliographical control is to wait on uniformity in cataloging codes it will not be achieved. The Prussian Instructions are not likely to be adopted in this country nor the Anglo-American Code in Germany, nor is a middle way acceptable to both countries probable. What we can look for, however, is that countries at present bibliographically unorganized will learn the methods of those that are comparatively advanced, so that diversity will not increase. Much might be done by what might be called the peaceful penetration of librarians and librarianship. American influence in the Vatican Library and its code, and in many lands by the distribution of Library of Congress cards, show what can be achieved. As for the question of control by periods, we would probably be thought for a time to be wanting in a sense of historical perspective. Our actions would in fact be based on a true appreciation of the needs of the future as well as on a realization of the importance of the present and the past. 